\title{
Colimitation of decomposition by substrate and decomposers - a comparison of model formulations
}

\author{
T. Wutzler and M. Reichstein \\ Max-Planck institute for Biogeochemistry, Jena, Hans Knöll Str. 10, 07745 Jena \\ Received: 29 November 2007 - Published in Biogeosciences Discuss.: 11 January 2008 \\ Revised: 8 April 2008 - Accepted: 21 April 2008 - Published: 13 May 2008
}

\begin{abstract}
Decomposition of soil organic matter (SOM) is limited by both the available substrate and the active decomposer community. The understanding of this colimitation strongly affects the understanding of feedbacks of soil carbon to global warming and its consequences. This study compares different formulations of soil organic matter (SOM) decomposition. We compiled formulations from literature into groups according to the representation of decomposer biomass on the SOM decomposition rate a) nonexplicit (substrate only), b) linear, and c) non-linear. By varying the SOM decomposition equation in a basic simplified decomposition model, we analyzed the following questions. Is the priming effect represented? Under which conditions is SOM accumulation limited? And, how does steady state SOM stocks scale with amount of fresh organic matter (FOM) litter inputs? While formulations (a) did not represent the priming effect, with formulations (b) steady state SOM stocks were independent of amount of litter input. Further, with several formulations (c) there was an offset of SOM that was not decomposed when no fresh OM was supplied. The finding that a part of the SOM is not decomposed on exhaust of FOM supply supports the hypothesis of carbon stabilization in deep soil by the absence of energy-rich fresh organic matter. Different representations of colimitation of decomposition by substrate and decomposers in SOM decomposition models resulted in qualitatively different long-term behaviour. A collaborative effort by modellers and experimentalists is required to identify formulations that are more or less suitable to represent the most important drivers of long term carbon storage.
\end{abstract}

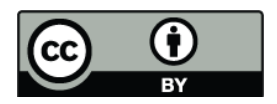

Correspondence to: T. Wutzler (twutz@bgc-jena.mpg.de)

\section{Introduction}

Plant litter or fresh organic matter (FOM) that enters the soil is decomposed by decomposer communities. In this process a part of the FOM is transformed to soil organic matter ( $\mathrm{SOM}$ ) and most of the carbon is released as $\mathrm{CO}_{2}$ to the atmosphere. The understanding of the colimitation of the decomposition of FOM and SOM by the available substrate and the decomposers strongly affects the understanding of feedbacks of soil carbon to global change (Fang et al., 2005) and hence the understanding and consequences of global change (Jones et al., 2005).

This article studies the long-term consequences of several modelling assumptions regarding the decomposition process. It answers the following question: What decomposition formulations have been applied in SOM decomposition models, what are their underlying assumptions, and how can they be classified? What are their long-term implication for soil carbon storage? This is approached first, by reviewing the assumptions of several formulations of decomposition and second, by comparing the steady states of a basic minimal model, in which the decomposition equation was modified.

The colimitation of decomposition is represented in various ways in models that describe decomposition at daily resolution at plot-scale (Sect. 3.1). However, the assumption of different decomposer communities that mutually independent decompose different kinds of substrates has led to a widely used representation of decomposition at decadal to millennial time scales that is focused on substrate only (Paustian et al., 1997).

The observation of the priming effect (e.g. Kuzyakov et al., 2000) challenges the assumption of independent decomposition. In the modelling context we define priming as the effect

Published by Copernicus Publications on behalf of the European Geosciences Union. 
that decomposition of one soil carbon pool is influenced by the dynamics of another soil carbon pool. Based on observations of priming Fontaine and Barot (2005) suggest a formulation of SOM decomposition that results in SOM accumulation that is only limited by nitrogen availability for the SOM decomposers. This implies a completely different long-term dynamics compared to most commonly used models, where the cabon pools at steady state are constant and depend linearly on the fresh organic matter input. This contradiction warrants a closer review of different representations of various used decomposition equations and their underlying assumptions.

There are several good reviews and comparisons of SOM decomposition models. Van Veen and Frissel (1981a) group models that particularly take account of the role of microorganisms in mineralization versus simplified models that are more generically applicable. Paustian (1994) contrast organism oriented versus process oriented models. McGill (1996) compares 10 process-based models against long term field data and propose a classification scheme. The scheme distinguishes amongst others for kinetic versus biochemical or functional litter and SOM compartmentalization, which relates to representation of decomposer biomass in the models. Molina and Smith (1998) give a good general introduction into the historical evolution and various concepts of SOM models. Smith et al. (1998) focus on the purpose of the various models and summarize the reviews of Paustian, McGill, and Molina and Smith. Paustian et al. (1997) compare shortterm decomposition and equilibrium states of several conceptual model formulations and three full models. Chertov et al. (2007) compare three conceptually different models against data from incubation studies. There are also more current reviews emphasizing on soil models for cropping systems (Shibu et al., 2006; Manlay et al., 2007), the stabilization by micro aggregates (Six et al., 2004), and the general role of soils (Yadav and Malanson, 2007).

However, all the above reviews are difficult to interpret in respect to different representations of colimitation of decomposition by substrate and decomposers because they compare full soil carbon models that differ in many aspects. Hence, this study reviews modelling literature with the explicit focus on this colimitation. Further, it compares various formulations by substituting them into a common basic model and by calculating the models steady states as a representation of the essentials of long-term behaviour. The study shows that that the long-term consequences of formulations of decomposition qualitatively differ by the representation of the active decomposer in the description of SOM decomposition.

\section{Methods}

In a first step we compiled formulations of SOM decomposition from literature and summarized their underlying assumptions. The original formulations were simplified in a way so that only the factors and terms relating to substrate and decomposer biomass were included. Other drivers such as temperature, moisture, soil texture or nutrient availability were assumed to be constant and lumped into constants.

We grouped the equations in three groups a) "nonexplicit", b) "linear", and c) "nonlinear" according to the representation of decomposer biomass in the SOM decomposition equations. In most cases this corresponded to similar assumptions and consequences for long term carbon storage.

In a second step we compared long-term consequences of the formulations. Following the conclusion of JansHammermeister and McGill (1997) we compared only one contrasting component of system models, in our case the decomposition equations. We accomplished this by setting up a simplified minimal model system (Sect. 2.1) and substituted different versions of decomposition equations into this common model. Next, we calculated carbon pool sizes and fluxes as a function of model parameters at system steady state. Steady state represented the essential characteristics of the long-term behaviour and long-term consequences of the formulation of SOM decomposition. The following questions were addressed.

- Is the priming effect simulated?

- Is the SOM accumulation limited, i.e. under which conditions does an steady state of SOM exist?

- How does the steady state of SOM scale with input of fresh organic matter (FOM)?

- Is there a positive steady state of SOM for FOM assimilation approaching zero?

Steady states were calculated analytically by setting the derivative of the model equations to zero. At a few cases the function of the steady state was not defined at zero litter input, and we hence calculated the limit of the function for litter input approaching zero.

\subsection{Model system}

In order to compare the different decomposition formulations, we inserted them into the same minimal SOM decomposition model. A flowchart of the system is given in Fig. 1. The minimal system considered only one pool of SOM $(S)$ of a single quality. The SOM was decomposed according to the equations $d_{s}$ that we compared. During decomposition a part $\epsilon$ of the decomposed SOM was assimilated by the active decomposers $A$ and the other part was repired as growth respiration. The carbon in active decomposers was respired as maintenance respiration $r$ or entered the SOM as a flux $s$ of microbial metabolites or dead microbial biomass. Both fluxed were described by a first order kinetics. Pool sizes were expressed in weight per volume $\left(\mathrm{kg} / \mathrm{m}^{3}\right)$ and the time was expressed in years. We assumed an additional source of carbon $i_{F}$ that is available to the active SOM decomposers. 
We were interested in the qualitative behaviour in steady state for a given input of FOM and given, i.e. constant, environmental conditions. Therefore, the minimal model abstracted from the effects of environmental conditions such as temperature, soil moisture or texture, on the various model parameters. Further the minimal model did not account for interactions with other elements such as nitrogen or phosphorus.

The system was described by the following equations.

$$
\begin{aligned}
& \frac{d A}{d t}=i_{F}+\epsilon d_{S}-(s+r) A \\
& \frac{d S}{d t}=s A-d_{S}
\end{aligned}
$$

\subsection{Artificial model calibration experiment}

In order to demonstrate that incubation priming experiments can be useful to discriminate between different model formulations, we devised an artificial model calibration experiment. We prescribed an initial amount and isotopic composition of SOM (7.0 kg, $\left.R_{C 14}=1 \mathrm{e}-12\right)$ and an pulse input of labelled FOM $\left(0.1 \mathrm{~kg}, R_{C 14}=10 \mathrm{e}-12\right)$. We used the model system (Eqs. 1-2) and decomposition formulation (10) to generate a timeseries of the amount of carbon in respired $\mathrm{CO}_{2}$ and its isotopic composition. Next, we added normaly distributed measurement errors to the timeseries ( $c v=40 \%$ for respiration and $s d=0.5 \mathrm{e}-10$ for isotopic ratio). First, we fitted the parameters of the model system with decomposition formulation (10) and with decomposition formulation (3) to the timeseries of respiration. Second, we refitted the parameters by a multiple constraint approach to both the amount of respiration and the isotopic ratio.

The likelihood of the model parameters for this gaussian case with no apriori information on the parameters can be expressed as $L=c \exp \left(-\frac{1}{2} S S\right)$, where $c$ is a constant and $S S$ is the weighted sum of sqared differences between the vectors of the model output and the artifical data: $S S=\left(g(\mathbf{m})-\mathbf{d}_{\mathrm{obs}}\right)^{t} \mathbf{C}_{\mathbf{D}}{ }^{-1}\left(g(\mathbf{m})-\mathbf{d}_{\mathrm{obs}}\right)$, where $g(\mathbf{m})$ is the model output for the optimized parameters $\mathbf{m}$, and $\mathbf{C}_{\mathbf{D}}$ is the variance-covariance matrix of the uncertainty of the observations $\mathbf{d}_{\mathrm{obs}}$, in our case the artificial data (Tarantola, 2005). If ratio of the maximum likelihoods of the two formulations $L_{\text {ModelA }} / L_{\text {ModelB }}$ increases with the multiple constraint analysis then the discrimination of the models is enhanced.

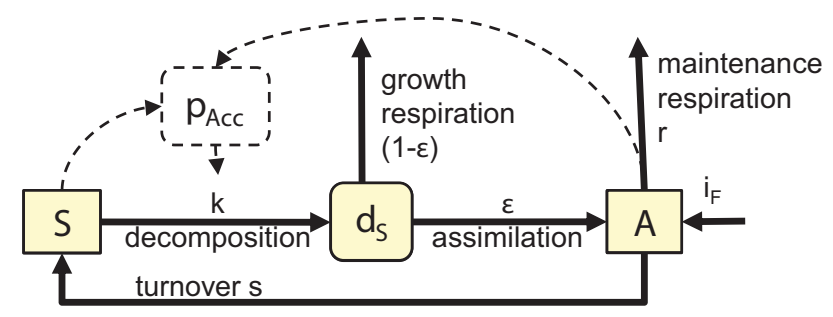

Fig. 1. Flowchart of the minimal decomposition model

\section{Results}

\subsection{Review of decomposition equations}

\subsubsection{Non-explicit representation of decomposer biomass in SOM decomposition}

The most widely applied formulation of substrate decomposition is first order kinetics (Eq. 3) e.g. (Grace et al., 2006; Franko, 1996; Verberne et al., 1990; Hansen et al., 1991; Parton et al., 1988; Li et al., 1992; Molina et al., 1983; Chertov et al., 2001; Liski et al., 2005; Corbeels et al., 2005). The decomposer biomass is not treated explicitly. The formulation assumes that substrate of each quality, i.e. the ease of mineralisation (Paustian et al., 1997), has it's own decomposer community associated with, and that this decomposer community is in equilibrium with the available substrate most of the time and therefore decomposition is only limited by substrate (McGill and Myers, 1987). Decomposition $d_{S}$ therefore scales linear with available substrate $S$.

$d_{S}=k S$

Microbiology studies of substrate decomposition, however, show that decomposition often follows standard enzyme kinetics (Paul and Clark, 1989), where the rate of decomposition saturates at a maximum rate with increasing substrate availability (Eq. 4). Hence, serveral models use Michaelis-Menten type equations (e.g., van Dam and van Breemen, 1995).

$d_{S}=k \frac{S}{k_{m}+S}$

Where, $S$ is the quantity of carbon in recalcitrant SOM, $k$ is the maximum decomposition rate and $k_{m}$ is the quantity of $S$ where decomposition rate is half of it's maximum.

\subsubsection{Linear representation of decomposer biomass in SOM decomposition}

The assumption that decomposition is limited by substrate only has been questioned (Fontaine and Barot, 2005). Fontaine states, that decomposition of recalcitrant SOM is 
limited by the quantity of enzymes and not by the quantity of substrate. With the assumption that the quantity of enzymes is proportional to quantity of carbon in the decomposer pool $A$ they propose Eq. 5, which was also already used by van Wensem et al. (1997).

$d_{S}=k A$

The first order kinetics (Eq. 3) and Fontaine's equation (Eq. 5) can be seen as two extremes of a colimitation of decomposition by substrate and decomposers. There are several equations that take into account both quantities. The probably simplest assumption is that decomposition is proportional to both quantities $A$ and $S$ (Eq. 6) (Manzoni and Porporato, 2007; Fang et al., 2005; Knapp et al., 1983).

$d_{S}=k A S$

According to Liebigs law of minimum Moorhead and Sinsabaugh (2006) use Eq. 7, which is the minimum of of Eq. 3 and Eq. 5, to describe decomposition. Also the formulation of a mass-action law to describe the fraction of the substrate that is decomposed by Neill and Gignoux (2006) essentially leads to a decomposition that is smaller or equal to this minimum.

$d_{S}=\min \left(k_{1} S, k A\right)$

A classic formulation (Monod, 1949) is based on standard enzyme kinetics (Eq. 8) with variable amounts of enzymes, which are assumed to be proportional to the quantity of decomposers. This formulation also has been frequently employed (Parnas, 1975; Smith, 1979; Van Veen and Frissel, 1981b; Ladd et al., 1995; Blagodatsky and Richter, 1998; Kersebaum and Richter, 1994).

$d_{S}=k A \frac{S}{k_{m}+S}$

3.1.3 Nonlinear representation of decomposer biomass in SOM decomposition

There are further formulations of colimitation that we distinguished from the previous ones because they are nonlinear in respect to the the decomposer quantity.

Besides standard enzyme kinetics, microbes may inhibit each other (Suzuki et al., 1989). This kinetics can be described by an increase of the $k_{m}$ constant with increasing microbial pool in the Monod-formulation (Eq. 8). Hence, Grant et al. (2001) applied Eq. 9 to SOM decomposition.

$d_{S}=k A \frac{S}{k_{m}\left(1+k_{i} A\right)+S}$
In a theoretical modelling study on the implications of exoenzyme activity on microbial carbon Schimel and Weintraub discussed several decomposition formulations (Schimel and Weintraub, 2003). They proposed that the decomposition rate saturates with increasing enzyme availability instead of increasing substrate availability. With accounting for variable amount of SOM they derived Eq. 10. The same equation has been used by other studies as well (Garnier et al., 2003; Raynaud et al., 2006). The formulation is structurally opposite to the formulation of Monod (Eq. 8), which saturates with increasing SOM availability.

$d_{S}=k S \frac{A}{k_{m}+A}$

Using a simple simulation experiment of spatial accessibility of microbial communities to a small soil volume Wutzler $(2008)^{1}$ inferred an exponential equation of the accessible proportion of the soil volume given the size of the decomposer pool. With the simplifying assumption that substrate is randomly distributed within a small soil volume, decomposition then can be described by Eq. 11 .

$d_{S}=k\left(1-e^{-c A}\right) S$

There are also more complex formulations of Eq. 12 in the ITE model (Arah, 1996) and Eq. 13 in the SOMKO model (Gignoux et al., 2001), for which we did not calculate equilibrium states.

$d_{S}=k A^{\frac{2}{3}} \frac{S}{k_{m}+S}\left(1-k_{u} \frac{A}{S}\right)$

$d_{S}=\left(1-e^{-k \frac{A}{S}}\right) S$

3.1.4 Formulations of SOM decomposition with additional states

Ågren and Bosatta (1996) propose a conceptual view of the decomposition process, that involves a continuous spectrum of quality of organic matter. Microbial access to the organic matter, decomposition rate, and microbial efficiency depend on the quality $q$ of a litter cohort (Eq. 14) that changes during decomposition.

$d_{S}=-k \frac{u(q)}{e(q)} S$

Blagodatsky and Richter (1998) propose a view on decomposition that depends on the proportion of active to dormant microbial biomass (Eq. 15). This proportion is expressed as

\footnotetext{
${ }^{1}$ Wutzler, T.: Microbial accessible space as a limitation of SOM decomposition., in preparation, 2008.
} 
Table 1. Steady state of soil organic matter $S^{*}$.

\begin{tabular}{|c|c|c|c|c|c|}
\hline equation & $d_{S}$ & priming & $S^{*}$ & scaling of $S^{*}$ with $i_{F}$ & $S^{*}$ at $i_{F} \rightarrow 0$ \\
\hline \multicolumn{6}{|c|}{ non-explicit representations of decomposer biomass } \\
\hline 3 & $k S$ & no & $\frac{i_{F} s}{((1-\epsilon) s+r) k}$ & linear & 0 \\
\hline 4 & $k_{\frac{1}{k_{m}+S}}$ & no & $\frac{i_{F} k_{m}}{\left((1-\epsilon)+\frac{r}{s}\right) k-i_{F}}$ & monotonous or $\infty$ & 0 \\
\hline \multicolumn{6}{|c|}{ linear representations of decomposer biomass } \\
\hline 5 & $k A$ & yes & $\infty$ & no & $S(t=0)$ \\
\hline 6 & $k A S$ & yes & $\frac{s}{k}$ & no & $\frac{s}{k}$ \\
\hline 7 & $\min \left(k_{1} S, k A\right)$ & yes & $\infty$ & no & $S(t=0)$ \\
\hline 8 & $k A \frac{S}{k_{m}+S}$ & yes & $\frac{k_{m} s}{k-s}$ & no & $\frac{k_{m} s}{k-s}$ \\
\hline \multicolumn{6}{|c|}{ nonlinear representations of decomposer biomass } \\
\hline 9 & $k A \frac{S}{k_{m}\left(1+k_{i} A\right)+S}$ & yes & $\frac{k_{m}\left(k_{i} A^{*}+1\right)}{\underline{k}-1}$ & linear & $\frac{k_{m}}{\underline{k}-1}$ \\
\hline 10 & $k S_{\frac{A}{k_{m}+A}}$ & yes & $\frac{s}{k}\left(A^{*}+k_{m}\right)$ & linear & $\frac{s}{k}$ \\
\hline 11 & $k S\left(1-e^{-c A}\right)$ & yes & $\frac{s A}{k}\left(1+\frac{1}{e^{c A}-1}\right)$ & monotonous & $\frac{s}{c k}$ \\
\hline
\end{tabular}

an activity state $r$ which in turn is expressed as an additional state variable. $r$ approaches a value that is a function of the substrate $\phi(S)$ (Eq. 16).

The formulations of SOM decomposition with additional states could not be represented with our minimal model. However, we refer to steady states in the original models in the discussion section.

$$
\begin{aligned}
d_{S} & =r k A \frac{S}{k_{m}+S} \\
\frac{d r}{d t} & =\rho(\phi(S)-r)
\end{aligned}
$$

\subsection{Steady states}

The steady state of the decomposer biomass $A^{*}$ is given by Eq. 18 for almost all the formulations. The only exception was formulation 5, where steady state of decomposer biomass follows Eq. 19. The constant $c_{1}$ introduced in equation 17 was introduced to simplify the equation 18 and the discussion of it. $c_{1}$ is always positive because $\epsilon<1, s>0$, and $r>0$.

$$
\begin{aligned}
c_{1} & =(1-\epsilon) s+r \\
A^{*} & =\frac{i_{F}}{c_{1}} \\
A^{*} & =\frac{i_{F}}{s+r-\epsilon k}
\end{aligned}
$$

The steady state for SOM $\left(S^{*}\right)$ for the various formulations is given in Table 1. Formulations that did not result in a steady state are depicted by the symbol $\infty$. Fig. 2 displays the effect of the assimilation of FOM $i_{F}$ on the steady state for $\operatorname{SOM}\left(S^{*}\right)$.

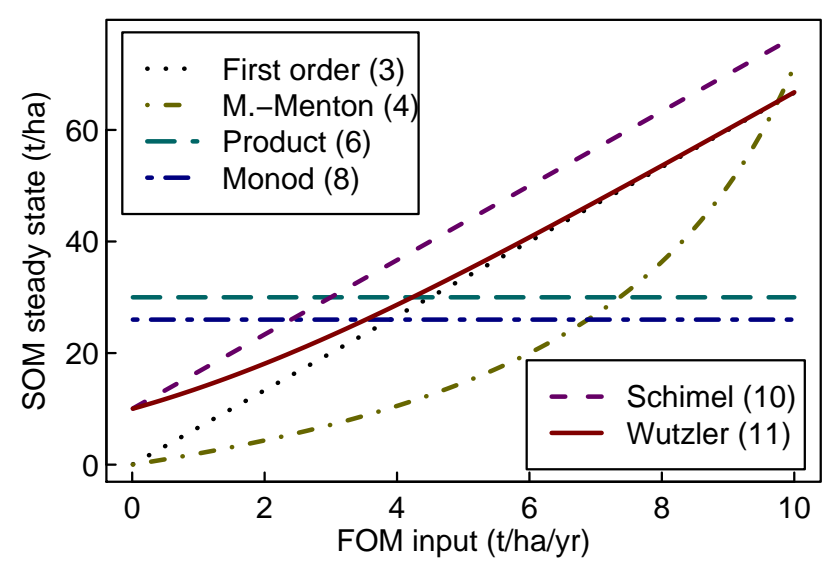

Fig. 2. Effect of assimilation rate of FOM $i_{F}$ on the steady state of $\operatorname{SOM}\left(S^{*}\right)$. The numbers refer to equations in the text.

Formulation 4 has a steady state when $i_{F} \leq \frac{c_{1} k}{s}$ but with $i_{F} \rightarrow \frac{c_{1} k}{s} S^{*}$ goes to $\infty$ and with larger $i_{F}$ there is unlimited SOM accumulation. In order to sustain biomass with formulation $5 \epsilon k<s+r$ is required. $S$ has no stable steady state but increases infinitely at a constant rate $(s-k) A^{*}$ for $s>k$. This rate scales with $i_{F}$ as does $A^{*}$ (Eq. 19). With the case $s<k$, SOM stocks would become depleted. With the minimum approach (Eq. 7) substrate limitation occurs only on small amounts of SOM. When the amount of SOM exceeds a minimum value, the decomposition is only limited by the decomposers and SOM accumulates infinitely like with formulation 5. With formulation $8 S^{*}$ is independent of $i_{F}$. It only exists if $s<k$, else there is infinite accumulation. The formulations 10 , and 11 , which are non-linear in respect to decomposer biomass $A^{*}$, exhibit a monotonous increase of steady state SOM $S^{*}$ with carbon inputs $i_{F}$ (Fig. 2). When 

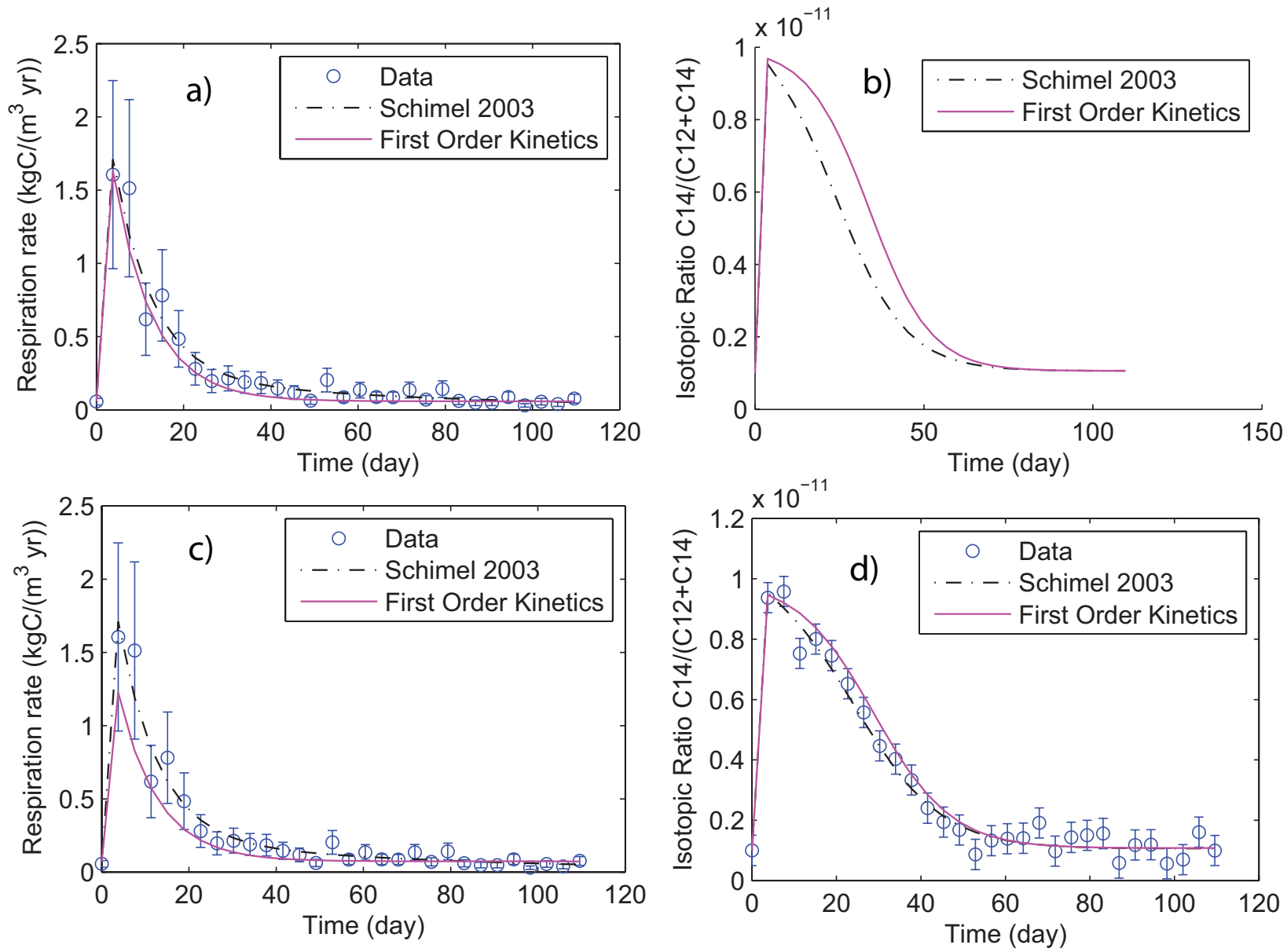

Fig. 3. Challenging models with experimental data. (a) and (b) Calibration against respiration data only. (c) and (d) Calibration against both respiration and isotopic ratio. The artificial data were generated by adding normally distributed random numbers to the simulation results of the model results which used formulation 10 (Schimel, 2003). Error bars represent standard deviation.

carbon inputs approach zero, also the decomposer biomass $A^{*}$ goes to zero. However, $S^{*}$ does not decrease to zero but stabilizes at a low level. Hence, in the absence of FOM assimilation there exists a fraction of SOM that is not decomposed. A similar behaviour is exhibited by formulation 9 for $k>s$, i.e. when decomposition is greater than the turnover of microbial biomass. For $s \rightarrow k, S^{*}$ approaches infinity. And for $k<s$ there is an infinite accumulation of SOM.

The continuous quality concept was not studied with our minimalistic model, which assumed only a single pool of SOM with given quality. Both, limited and unlimited accumulation can be simulated with the continuous quality concept. The result depends on the specification of the functions of microbial efficiency $e(q)$, and the specific growth rate $u(q)$ (Ågren and Bosatta, 1996). However, currently the priming effect is not simulated. All cohorts, i.e. carbon that entered the soil within the same time frame, decompose independently.

The steady state $r$ in the model of Blagodatsky and Richter (1998) is given by $\phi\left(S^{*}\right)$ Eq. 15 and Eq. 16 . In the origi- nal model also the turnover of the microbes is modified by $r$. With assuming a constant microbial turnover formulation 15 yields qualitatively same results for steady state as the Monod-kinetics (Eq. 8).

\subsection{Artificial model calibration experiment}

When using respiration data alone, it was hard to distinguish between the decomposition formulations (10) and (3) in the artificial model calibration experiment (Fig. 3a). However, the prediction of the isotopic ratio of the respired $\mathrm{CO}_{2}$ differed considerable (Fig. 3b). Hence, explicitly modelling the isotopic ratio and calibrating the models to both outputs, resulted already in a better discrimination of the models. The model of first order kinetics (3) slightly, but consistently underestimated the respiration during days 5 to 40 (Fig. 3c) and overestimated the isotopic ratio during these days (Fig. 3d).

The better discrimination between the formulations with the multiple constraint opimization was also seen in the ratio of the likelihoods of the two formulations. The maximum likelihood ratio (Schimel formulation 10/substrate first order 
formulation 3) was 1.5 with the fit to the amount of respiration alone, but it was $7.6 \mathrm{e} 11$ with the additional inclusion of the isotopic ratio of the respiration.

\section{Discussion}

Our study provides the first review and comparison of soil organic matter decomposition models that explicitly focuses on the colimitation of decomposition by substrate and decomposers.

By abstracting from other factors such as fluctuations in environmental conditions or nutrient availability and by using a basic minimalistic model for all the equations, we could show that long term consequences of formulations do differ qualitatively. These differences could be grouped according to the assumptions about decomposer biomass and to the resulting representation of decomposer biomass in the decomposition equation.

\subsection{Priming effect and steady states}

The priming effect, i.e. the decomposition of SOM is influenced by the assimilation of FOM, was simulated with all formulations of SOM decomposition that accounted for active microbial biomass in an explicit manner (Table 1). The non-explicit formulations, used in many models (Sect. 3.1.1) were based on the assumption that decomposition of SOM can be considered in equilibrium with the available SOM at timescales larger than a few month (Paustian et al., 1997). If, however, the active SOM decomposers can feed on an additional carbon source related to FOM, this assumption does not longer hold. Contrary, the active decomposer biomass is near an equilibrium with the assimilation of FOM $i_{F}$. Hence, in order to simplify models at larger time scales, we suggest to replace active decomposer biomass in model decomposition equations with the assimilation flux $i_{F}$ and then simplify the system equations.

There was a finite steady state of SOM $S^{*}$ with all formulations except the formulations 5 and 7 . With the latter equations and also with formulations 4, 8, and 9 an unlimited accumulation of SOM was possible. In these cases other factors must limit SOM accumulation in order to not lock away all nutrients in SOM. Fontaine and Barot (2005) showed that competition for nitrogen between different microbial functional groups eventually limits carbon assimilation. Especially in older ecosystems also other nutrients such as phosphorus might be important. With these formulations the long-term balance is not determined by the quantity of litter input and decomposition rates only. Rather, parameters of the nitrogen cycle and nitrogen deposition become important. However, the understanding of nitrogen cycle is not equivocal in literature. For example there are competing hypothesis about direct or indirect nitrogen uptake (Manzoni and Porporato, 2007), damping or amplification of the priming effect by nitrogen fertilization (Fontaine et al., 2004; Conde et al., 2005), and the role of plants in competition for organic nitrogen (Schimel and Bennett, 2004). Further the nitrogen cycle may be strongly influenced by micro sites (Li et al., 2000). Hence, we expect that it will be hard to falsify the hypothesis of SOM accumulation to be limited by nitrogen.

The equilibrium state of SOM increased monotonically with input of fresh organic matter (FOM) in the non-explicit group of SOM decomposition formulations and the nonlinear group of formulations (Table 1). Contrary, with all formulations within the linear group the steady state was independent of FOM. This independence seems to contradict observations of environmental gradients of litter inputs, which are assumed to correlate with primary production, where carbon stocks are increasing with input of carbon (Jobbagy and Jackson, 2000; Paul et al., 1997). One argument was, that this positive correlation between primary production and SOM stocks is not due to litter production but due to other confounding factors. We believe, that this arguement is unlikely, because temperature, the most important other factor, usually also increases with primary productivity. The temperature increase leads to increasing decomposition rates and possibly lower SOM stocks instead of higher SOM stocks (Table 1 Eq. 7).

The steady state for the case when FOM assimilation approached zero differed between the groups of formulations. Within the non-explicit group of formulations SOM steady state $S^{*}$ was zero, i.e., all SOM is eventually decomposed (Fig. 2). With all the other formulations, there was an offset for SOM steady state $S^{*}$ for reasonable model parameterization and initial conditions. For the formulations 5 and 7, which did not lead to a general steady state, the amount of the SOM pool did not change and stayed at the amount before FOM assimilation decreased to zero (Table 1). For the formulations in the non-linear group, the SOM pool decreased but approached a positive amount. Hence, there was a part of the SOM that is not decomposed at all in the absence of available fresh organic matter. This finding corresponds to observations of Fontaine et al. (2007) of millenia-years old carbon (Rumpel et al., 2002; Jobbagy and Jackson, 2000) in deeper soil layers where FOM supply is very low (von Lützow et al., 2006). It also corresponds to observations of litter bag studies, which can be best modelled by inferring a limit of decomposition where there is a part of the initial mass that is not decomposed in finite time (e.g. Berg et al., 1996; Bottner et al., 2000).

The strength of the approach of using a common basic model to compare different formulations of SOM decomposition is also its biggest limitation. We could not compare the behaviour of the continuous quality model (Ågren and Bosatta, 1996) and the activity state model (Blagodatsky and Richter, 1998). The abstraction from other factors such as temperature, moisture, and nutrients discards aspects that are important in the original context of the equations. However, inclusion of other aspects would yield in more complex and 
quantitatively larger differences in the steady state behaviour of the different models.

\subsection{Relation with temperature sensitivity}

The formulations of decomposition based on substrate only have lead to the models with the smallest number of state variables and parameters, properties that are favourable in modelling. However, the assumptions that decomposer biomass is in equilibrium with the SOM pool neglects the priming effect and results in long-term behaviour that can explain very old carbon only by assuming a very low intrinsic decomposability. With these equations the decomposition of old carbon is primarily controlled by the temperature sensitivity of the old carbon (e.g. Reichstein et al., 2005).

Contrary, temperature sensitivity may be overruled by other factors when explicitly modelling the priming effect by a second food source to the SOM decomposers and when explicitly accounting for decomposers in the SOM decomposition. The steady steate of old SOM depends either on other limiting factors such as nitrogen (Fontaine and Barot, 2005) (linear group of formulation). Or it depends on the availability of energy-rich fresh organic matter, belowground litter, or root exudates (Godbold et al., 2006; Göttlicher et al., 2006) which vary with soil depth (Bruun et al., 2007; Rasse et al., 2006; Gill and Burke, 2002; Frey et al., 2003; Elzein and Balesdent, 1995) (nonlinear group of formulation). The latter dependency is sensitive to land use changes, management practices and soil perturbations.

The importance of temperature sensitivity of SOM decomposition strongly affects our understanding of the feedback of SOM to global warming. We conclude that it is necessary to study which assumptions and which formulations of decomposition are more or less suitable to represent the most important drivers for long term carbon balance.

4.3 Challenging models with experiments to discriminate among formulations

In the following section we discuss approaches of discriminating among the different formulations. Often experiments are designed to calibrate a given model, or a model is designed to explain the observed data. Most of the cited models have been repeatedly compared to observations that were collected to validate the model. However, science usually works the opposite direction where inappropriate hypotheses are falsified or ranked down by comparison against observation data Popper (1934); Kuhn (1962); Lakatos (1977). Therefore, we argue to design experiments in a way that models can be falsified in the best way (Hunter and Reiner, 1965; Atkinson and Donev, 1992; Reynolds and Ford, 1999). When sorting out models that are less suitable to explain the observed data, we also challenge the assumptions that underlie the models and the formulations of SOM decomposition.
The first idea of discriminating among the models is to challenge the long-term behaviour of the models (Fig. 2) by observations of carbon stocks for soil that are assumed to be in steady state and to compare the scaling of the soil carbon stocks with the mean litter input. The finding of increasing SOM stocks with increasing primary productivity and litter input (Jobbagy and Jackson, 2000; Paul et al., 1997) renders the formulations in the linear group unlikely. However, we already discussed the possible influence of confounding environmental factors. The effect of temperature, soil moisture, texture and structure has to explicitly accounted for in both observations and modelling. Further, the assumption that recently undisturbed soils are near steady state has be questioned, because of the long turnover times of the slow carbon pools (Wutzler and Reichstein, 2007).

Hence, we suggest to study the transient behaviour of soil under laboratory conditions, where the confounding factors and the input of fresh organic matter are controlled. We propose to challenge models by observations of patterns of several variables, which is used in multiple constraint model identification (Raupach et al., 2005; Reichstein et al., 2003) or pattern oriented modelling (Wiegand et al., 2003). The inclusion of the isotopic ratio in addition to the amount of respiration clearly improved the identifiability of model formulations in the artificial model discrimination experiment. However, the addition of the isotopic ratio might not sufficient in other cases and we need to look for additional measures and patterns. A closer collaboration between soil scientists, microbiologists, modellers, and experimentalists is required to set up sound models and experiments in order to solve the model identification task.

If experiments can show that the priming effect is important for the long-term dynamics of SOM, the formulations of the non-explict group are less suitable to describe long-term SOM dynamics. The discussion on the positive correlation between litter input and steady state SOM stocks rendered also the formulations of the linear group unlikely. Hence, we argue that the formulations of SOM decomposition where the active decomposers are represented in a nonlinear manner are most suitable to describe long-term SOM dynamics.

\section{Conclusions}

This study reviews and compares different assumptions and formulations of colimitation of SOM decomposition by substrate and decomposers. The substitution of several formulations into a common basic model and the calculation of steady states enabled to compare the long term consequences of the formulations and their underlying assumptions. We showed that the consequences of various formulations can be grouped according to the representation of active decomposer biomass in the decomposition of SOM.

- The assumption that decomposition kinetics of various OM pools is independent of each other together with 
the assumptions that decomposers are quickly in steady state with substrate supply leads to formulation of decomposition that use substrate only. The priming effect is not simulated and SOM pools eventually decrease to zero on exhaust of FOM supply.

- The assumption that SOM decomposition is linearly related to decomposer biomass leads to steady states of soil organic matter that are independent of assimilation of FOM. Other factors such as nutrient limitation must be invoked to limit carbon sequestration.

- Several non-linear formulations of SOM decomposition exhibit similar steady state behaviour. Steady state SOM stocks increase monotonous with supply of FOM. At the exhaust of FOM assimilation, the decomposition is slowed down and there is a fraction of the SOM which is not decomposed.

Various assumptions lead to qualitatively different longterm behaviour of soil organic matter dynamics. In order to resolve these contradictive consequences, a combined effort of experimentalists and modellers is needed to identify which of the competing assumptions and models are suitable for describing long term carbon dynamics for which soils. If one accepts the assumptions that the priming effect is quantitatively important for SOM dynamics and that the steady state SOM stocks increase with litter input, then we argue that the formulations of SOM decompositions, where the active decomposers are represented in a nonlinear manner are most suitable to describe long-term SOM dynamics.

Acknowledgements. We want to thank Pete Smith and Sébastien Fontaine for their encouraging and constructive comments.

Edited by: J. Middelburg

\section{References}

Ågren, G. and Bosatta, E.: Theoretical ecosystem ecology - Understanding element cycles, Cambridge University Press, Cambridge, 1996.

Arah, J. R. M.: The soil submodel of the ITE (Edinburgh) forest and hurley pasture models, in: Evaluation of soil organic matter models, edited by Powlson, D. S., Smith, P., and Smith, J. U., vol. 38 of NATO ASI Series, Springer, Berlin, 1996.

Atkinson, A. and Donev, A.: Optimum Experimental Designs, vol. 8 of Oxford Statistical Sciences Series, Oxford University Press, Oxford, 1992.

Berg, B., Ekbohm, G., Johansson, M. B., McClaugherty, C., Rutigliano, F., and DeSanto, A. V.: Maximum decomposition limits of forest litter types: A synthesis, Canadian Journal of Botany-Revue Canadienne De Botanique, 74, 659-672, 1996.

Blagodatsky, S. A. and Richter, O.: Microbial growth in soil and nitrogen turnover: A theoretical model considering the activity state of microorganisms, Soil Biology and Biochemistry, 30, 1743-1755, 1998.
Bottner, P., Couteaux, M. M., Anderson, J. M., Berg, B., Billes, G., Bolger, T., Casabianca, H., Romanya, J., and Rovira, P.: Decomposition of C-13-labelled plant material in a European 65-40 degrees latitudinal transect of coniferous forest soils: simulation of climate change by translocation of soils, Soil Biology and Biochemistry, 32, 527-543, 2000.

Bruun, S., Christensen, B. T., Thomsen, I. K., Jensen, E. S., and Jensen, L. S.: Modeling vertical movement of organic matter in a soil incubated for 41 years with C-14 labeled straw, Soil Biology and Biochemistry, 39, 368-371, 2007.

Chertov, O. G., Komarov, A. S., Nadporozhskaya, M., Bykhovets, S. S., and Zudin, S. L.: ROMUL - a model of forest soil organic matter dynamics as a substantial tool for forest ecosystem modeling, Ecological Modelling, 138, 289-308, 2001.

Chertov, O. G., Komarov, A. S., and Nadporozhskaya, M. A.: Analysis of the dynamics of plant residue mineralization and humification in soil, Eurasian Soil Science, 40, 140-148, 2007.

Conde, E., Cardenas, M., Ponce-Mendoza, A., Luna-Guido, M. L., Cruz-Mondragón, C., and Dendooven, L.: The impacts of inorganic nitrogen application on mineralization of C-14-labelled maize and glucose, and on priming effect in saline alkaline soil, Soil Biology and Biochemistry, 37, 681-691, 2005.

Corbeels, M., McMurtrie, R. E., Pepper, D. A., and O'Connell, A. M.: A process-based model of nitrogen cycling in forest plantations: Part I. Structure, calibration and analysis of the decomposition model, Ecological Modelling, 187, 426-448, 2005.

Elzein, A. and Balesdent, J.: Mechanistic Simulation of VerticalDistribution of Carbon Concentrations and Residence Times in Soils, Soil Science Society of America Journal, 59, 1328-1335, 1995.

Fang, C., Smith, P., Smith, J. U., and Moncrieff, J. B.: Incorporating microorganisms as decomposers into models to simulate soil organic matter decomposition, Geoderma, 129, 139-146, 2005.

Fontaine, S. and Barot, S.: Size and functional diversity of microbe populations control plant persistence and long-term soil carbon accumulation, Ecology Letters, 8, 1075-1087, 2005.

Fontaine, S., Bardoux, G., Abbadie, L., and Mariotti, A.: Carbon input to soil may decrease soil carbon content, Ecology Letters, 7, 314-320, 2004.

Fontaine, S., Barot, S., Barré, P., Bdioui, N., Mary, B., and Rumpel, C.: Stability of organic carbon in deep soil layers controlled by fresh carbon supply, Nature, 450, 277-U10, 2007.

Franko, U.: Modelling approaches of soil organic matter turnover withing the CANDY system, in: Evaluation of soil organic matter models, edited by Powlson, D. S., Smith, P., and Smith, J. U., vol. 38 of NATO ASI Series, Springer, Berlin, 1996.

Frey, S. D., Six, J., and Elliott, E. T.: Reciprocal transfer of carbon and nitrogen by decomposer fungi at the soil-litter interface, Soil Biology and Biochemistry, 35, 1001-1004, 2003.

Garnier, P., Neel, C., Aita, C., Recous, S., Lafolie, F., and Mary, B.: Modelling carbon and nitrogen dynamics in a bare soil with and without straw incorporation, European Journal of Soil Science, 54, 555-568, 2003.

Gignoux, J., House, J., Hall, D., Masse, D., Nacro, H. B., and Abbadie, L.: Design and test of a generic cohort model of soil organic matter decomposition: the SOMKO model, Global Ecology and Biogeography, 10, 639-660, 2001.

Gill, R. A. and Burke, I. C.: Influence of soil depth on the decomposition of Bouteloua gracilis roots in the shortgrass steppe, Plant 
and Soil, 241, 233-242, 2002.

Godbold, D. L., Hoosbeek, M. R., Lukac, M., Cotrufo, M. F., Janssens, I. A., Ceulemans, R., Polle, A., Velthorst, E. J., Scarascia-Mugnozza, G., De Angelis, P., Miglietta, F., and Peressotti, A.: Mycorrhizal hyphal turnover as a dominant process for carbon input into soil organic matter, Plant and Soil, 281, 15-24, 2006.

Göttlicher, S. G., Steinmann, K., Betson, N. R., and Hogberg, P.: The dependence of soil microbial activity on recent photosynthate from trees, Plant and Soil, 287, 85-94, 2006.

Grace, P. R., Ladd, J. N., Robertson, G. P., and Gage, S. H.: SOCRATES-A simple model for predicting long-term changes in soil organic carbon in terrestrial ecosystems, Soil Biology and Biochemistry, 38, 1172-1176, 2006.

Grant, R. F., Juma, N. G., Robertson, J. A., Izaurralde, R. C., and McGill, W. B.: Long-term changes in soil carbon under different fertilizer, manure, and rotation: Testing the mathematical model ecosys with data from the Breton plots, Soil Science Society of America Journal, 65, 205-214, 2001.

Hansen, S., Jensen, H. E., Nielsen, N. E., and Svendsen, H.: Simulation of nitrogen dynamics and biomass production in winterwheat using the danish simulation-model Daisy, Fertilizer Research, 27, 245-259, 1991.

Hunter, W. and Reiner, A.: Methods for Discriminating Between Two Rival Models, Technometrics, 7, 307-323, 1965.

Jans-Hammermeister, D. C. and McGill, W. B.: Evaluation of three simulation models used to describe plant residue decomposition in soil, Ecological Modelling, 104, 1-13, 1997.

Jobbagy, E. G. and Jackson, R. B.: The vertical distribution of soil organic carbon and its relation to climate and vegetation, Ecological Applications, 10, 423-436, 2000.

Jones, C., McConnell, C., Coleman, K., Cox, P., Falloon, P., Jenkinson, D., and Powlson, D.: Global climate change and soil carbon stocks; predictions from two contrasting models for the turnover of organic carbon in soil, Global Change Biology, 11, 154-166, 2005.

Kersebaum, K. and Richter, O.: A model approach to simulate C and $\mathrm{N}$ transformations through microbial biomass, in: Nitrogen mineralizationin agricultural soils, edited by Neeteson, J. and Hassink, J., pp. 221-230, AB-DLO, Haren, The Netherlands, 1994.

Knapp, E. B., Elliott, L. F., and Campbell, G. S.: Carbon, nitrogen and microbial biomass interrelationships during the decomposition of wheat straw - a mechanistic simulation-model, Soil Biology and Biochemistry, 15, 455-461, 1983.

Kuhn, T.: The Structure of Scientific Revolutions, University of Chicago Press, Chicago, 1962.

Kuzyakov, Y., Friedel, J. K., and Stahr, K.: Review of mechanisms and quantification of priming effects, Soil Biology and Biochemistry, 32, 1485-1498, 2000 .

Ladd, J. N., Amato, M., Grace, P. R., and van Veen, J. A.: Simulation of $14 \mathrm{C}$ turnover through the microbial biomass in soils incubated with 14C-labelled plant residues, Soil Biology and Biochemistry, 27, 777-783, 1995.

Lakatos, I.: The Methodology of Scientific Research Programmes, vol. 1 of Philosophical Papers, Cambridge University Press, Cambridge, 1977.

Li, C. S., Frolking, S., and Frolking, T. A.: A model of nitrous-oxide evolution from soil eriven by rainfall events .1. model structure and sensitivity, Journal of Geophysical Research-Atmospheres, 97, 9759-9776, 1992

Li, C. S., Aber, J., Stange, F., Butterbach-Bahl, K., and Papen, H.: A process-oriented model of $\mathrm{N} 2 \mathrm{O}$ and $\mathrm{NO}$ emissions from forest soils: 1. Model development, Journal of Geophysical ResearchAtmospheres, 105, 4369-4384, 2000.

Liski, J., Palosuo, T., Peltoniemi, M., and Sievanen, R.: Carbon and decomposition model Yasso for forest soils, Ecological Modelling, 189, 168-182, 2005.

Manlay, R. J., Feller, C., and Swift, M. J.: Historical evolution of soil organic matter concepts and their relationships with the fertility and sustainability of cropping systems, Agriculture Ecosystems \& Environment, 119, 217-233, 2007.

Manzoni, S. and Porporato, A.: Theoretical analysis of nonlinearities and feedbacks in soil carbon and nitrogen cycles, Soil Biology and Biochemistry, 39, 1542-1556, 2007.

McGill, W. B.: Review and classification of ten soil organic matter (SOM) models, in: Evaluation of soil organic matter models using existing, long-term datasets, edited by Powlson, D. S., Smith, P., and Smith, J. U., vol. 38 of NATO ASI series I, pp. 111-132, Springer, Berlin Heidelberg New York, 1996.

McGill, W. B. and Myers, R. J. K.: Controls on dynamics of soil and fertilizer nitrogen, in: Soil fertility and organic matter as critical components of production systems, edited by Follet, R. F., Stewart, J. W. B., and Cole, C. V., pp. 73-99, SSSA/ASA, Madison, 1987.

Molina, J. A. E. and Smith, P.: Modelling carbon and nitrogen processes in soils., Adv. Agron., 62, 253-298, 1998.

Molina, J. A. E., Clapp, C. E., Shaffer, M. J., Chichester, F. W., and Larson, W. E.: Ncsoil, a model of nitrogen and carbon transformations in soil - description, calibration, and behavior, Soil Science Society of America Journal, 47, 85-91, 1983.

Monod, J.: The growth of bacterial cultures, Annual Review of Microbiology, 3, 371-394, 1949.

Moorhead, D. L. and Sinsabaugh, R. L.: A theoretical model of litter decay and microbial interaction, Ecological Monographs, 76, 151-174, 2006.

Neill, C. and Gignoux, J.: Soil organic matter decomposition driven by microbial growth: A simple model for a complex network of interactions, Soil Biology \& Biochemistry, 38, 803-811, 2006.

Parnas, H.: Model for decomposition of organic material by microorganisms, Soil Biology \& Biochemistry, 7, 161-169, 1975.

Parton, W. J., Stewart, J. W. B., and Cole, C. V.: Dynamics of C, N, $\mathrm{P}$ and $\mathrm{S}$ in grassland soils - a model, Biogeochemistry, 5, 109131,1988

Paul, E. A. and Clark, F.: Soil microbiology and biochemistry, Academic Press, San Diego, 1989.

Paul, E. A., Paustian, K., Elliott, E. T., and Cole, C. V.: Soil organic matter in temperate agroecosystems - long-term experiments in North America, CRC Press, Boca Raton, 1997.

Paustian, K.: Modelling soil biology and biochemical processes for sustainable agricultural research, in: Soil Biota. Management in Sustainalbe Farming Systems, edited by Pankhurst, C., Doube, B., Gupta, V., and Grace, P. R., CSIRO Information Services, Melbourne, 1994.

Paustian, K., Ågren, G. I., and Bosatta, E.: Modelling litter quality effects on decomposition and soil organic matter dynamics, in: Driven by nature: plant litter quality and decomposition, edited by Cadish, G. and Giller, G. E., CABI, Wallingford, UK, 1997. 
Popper, K.: The logic of scientific discovery (Logik der Forschung, amplified english edition 1959), Springer, Vienna, 1934.

Rasse, D. P., Mulder, J., Moni, C., and Chenu, C.: Carbon turnover kinetics with depth in a french loamy soil, Soil Science Society of America Journal, 70, 2097-2105, 2006.

Raupach, M. R., Rayner, P. J., Barrett, D. J., DeFries, R. S., Heimann, M., Ojima, D. S., Quegan, S., and Schmullius, C. C.: Model-data synthesis in terrestrial carbon observation: methods, data requirements and data uncertainty specifications, Global Change Biology, 11, 378-397, 2005.

Raynaud, X., Lata, J. C., and Leadley, P. W.: Soil microbial loop and nutrient uptake by plants: a test using a coupled $\mathrm{C}: \mathrm{N}$ model of plant-microbial interactions, Plant and Soil, 287, 95-116, 2006.

Reichstein, M., Tenhunen, J., Roupsard, O., Ourcival, J. M., Rambal, S., Miglietta, F., Peressotti, A., Pecchiari, M., Tirone, G., and Valentini, R.: Inverse modeling of seasonal drought effects on canopy $\mathrm{CO} 2 / \mathrm{H} 2 \mathrm{O}$ exchange in three Mediterranean ecosystems, Journal of Geophysical Research-Atmospheres, 108, 2003.

Reichstein, M., Katterer, T., Andren, O., Ciais, P., Schulze, E. D., Cramer, W., Papale, D., and Valentini, R.: Temperature sensitivity of decomposition in relation to soil organic matter pools: critique and outlook, Biogeosciences, 2, 317-321, 2005, http://www.biogeosciences.net/2/317/2005/.

Reynolds, J. H. and Ford, E. D.: Multi-criteria assessment of ecological process models, Ecology, 80, 538-553, 1999.

Rumpel, C., KÃđIgel-Knabner, I., and Bruhn, F.: Vertical distribution, age, and chemical composition of organic, carbon in two forest soils of different pedogenesis, Organic Geochemistry, 33, 1131-1142, 2002.

Schimel, J. P. and Bennett, J.: Nitrogen mineralization: Challenges of a changing paradigm, Ecology, 85, 591-602, 2004.

Schimel, J. P. and Weintraub, M. N.: The implications of exoenzyme activity on microbial carbon and nitrogen limitation in soil: a theoretical model, Soil Biology and Biochemistry, 549-563, 2003.

Shibu, M. E., Leffelaar, P. A., Van Keulen, H., and Aggarwal, P. K.: Quantitative description of soil organic matter dynamics - A review of approaches with reference to rice-based cropping systems, Geoderma, 137, 1-18, 2006.

Six, J., Bossuyt, H., Degryze, S., and Denef, K.: A history of research on the link between (micro)aggregates, soil biota, and soil organic matter dynamics, Soil \& Tillage Research, 79, 7-31, 2004.

Smith, O. L.: Analytical model of the decomposition of soil organic-Matter, Soil Biology and Biochemistry, 11, 585-606, 1979.

Smith, P., Andren, O., Brussaard, L., Dangerfield, M., Ekschmitt, K., Lavelle, P., and Tate, K.: Soil biota and global change at the ecosystem level: describing soil biota in mathematical models, Global Change Biology, 4, 773-784, 1998.
Suzuki, I., Lizama, H. M., and Tackaberry, P. D.: Competitiveinhibition of ferrous iron oxidation by Thiobacillus-Ferrooxidans by increasing concentrations of cells, Applied and Environmental Microbiology, 55, 1117-1121, 1989.

Tarantola, A.: Inverse Problems Theory, Methods for Data Fitting and Model Parameter Estimation, SIAM, Philadelphia, staple, 2005.

van Dam, D. and van Breemen, N.: NICCCE - a model for cycling of nitrogen and carbon isotopes in coniferous forest ecosystems, Ecological Modelling, 79, 255-275, 1995.

Van Veen, J. A. and Frissel, M.: Simulation of nitrogen behaviour of soil-plant systems, Pudoc, Centre for Agricultural Publishing and Documentation, Wageningen, 1981a.

Van Veen, J. A. and Frissel, M.: Simulation model of the behaviour of $\mathrm{N}$ in soil, in: Simulation of nitrogen behaviour of soil-plant systems, edited by Van Veen, J. A. and Frissel, M., pp. 126-144, Pudoc, Centre for Agricultural Publishing and Documentation, Wageningen, 1981b.

van Wensem, J., van Straalen, N. M., and Kooijman, S.: Carbon and nitrogen fluxes in decomposing leaf litter with microbialdetritivore interactions: Model simulations compared to microcosm ecotoxicity tests, Ecological Modelling, 96, 175-189, 1997.

Verberne, E. L. J., Hassink, J., Dewilligen, P., Groot, J. J. R., and Vanveen, J. A.: Modeling organic-matter dynamics in different soils, Netherlands Journal of Agricultural Science, 38, 221-238, 1990.

von Lützow, M., Kägel-Knabner, I., Ekschmitt, K., Matzner, E., Guggenberger, G., Marschner, B., and Flessa, H.: Stabilization of organic matter in temperate soils: mechanisms and their relevance under different soil conditions - a review, European Journal of Soil Science, 57, 426-445, 2006.

Wiegand, T., Jeltsch, F., Hanski, I., and Grimm, V.: Using patternoriented modeling for revealing hidden information: a key for reconciling ecological theory and application, Oikos, 100, 209222, 2003.

Wutzler, T. and Reichstein, M.: Soils apart from equilibrium - consequences for soil carbon balance modelling, Biogeosciences, 4, 125-136, 2007, http://www.biogeosciences.net/4/125/2007/.

Yadav, V. and Malanson, G.: Progress in soil organic matter research: litter decomposition, modelling, monitoring and sequestration, Progress in Physical Geography, 31, 131-154, 2007. 